\title{
DEVELOPMENT WITH CHARACTERISTICS AND INNOVATION - CONFUCIUS INSTITUTE AT LBUS
}

\author{
WANG Jiong ${ }^{1,2}$ \\ ${ }^{1}$ Beijing Language and Culture University, 15 Xueyuan Road, Haidian District \\ Beijing 100083, P. R. China, wangjiong@blcu.edu.cn; \\ ${ }^{2}$ Lucian Blaga University of Sibiu, 10 Victoriei Street, Sibiu, România, wang.jiong@lbusibiu.ro
}

\begin{abstract}
The research is on how to manage language teaching and culture promotion effectively through building explicit characteristics and seeking for innovative development of the program for the purpose of mutual understanding and common prosperity, taking Confucius Institute of Lucian Blaga University of Sibiu (LBUS) as an example. A brief introduction of the overall development of Chinese teaching program in the world and specifically in Romania will be conducted in the first part of the thesis. And then, characteristics of C.I. at LBUS in teaching and culture promotion will be discussed with detailed elaboration and progresses especially in the past five years. In the third part, some innovative ideas to accelerate the development of management will be proposed for more practical purpose. The conclusion provokes further research in managing language teaching and culture promotion overseas. KEYWORDS: characteristics; innovative development; Confucius Institute.
\end{abstract}

\section{BRIEF INTRODUCTION TO CHINESE TEACHING IN THE WORLD AND IN ROMANIA}

International Chinese education is an important public language and culture product provided by China to the world (according to Ministry of Education of P.R.C., 2021 [1]). Thanks to the continuous cooperation and joint efforts of both Chinese and foreign partners, the international Chinese language education has developed vigorously and achieved remarkable results. Up to now, more than 1,500 Confucius Institutes and Confucius Classrooms have been established in 159 countries through Sino-foreign cooperation, and more than 13 million students of various types have been trained. More than 180 countries have launched Chinese language education projects, 75 countries have included Chinese language in their national education systems (in 2016, Ministry of Education of Romania has included Chinese language in the national education system [2]) by issuing laws and decrees, more than 4,000 universities have established Chinese departments, majors (the Chinese major of LBUS is the first in the world set outside of China with the help of Confucius Institute, but it is still English + Chinese major now), and courses, and more than 75,000 mainstream primary and secondary schools, Chinese language Schools and training institutions offer Chinese courses. According to incomplete statistics, there are currently more than 25 million people studying Chinese in the world, and the cumulative number of learners and users is close to 200 million. Starting from 2021, Chinese language has become the official language of the United Nations World Tourism Organization. The role of Chinese in international communication has become increasingly prominent, and the international influence of Chinese has continued to rise.

Chinese teaching started long time ago in Romania since Romania was among the first group of countries setting up diplomatic relationship with new China in 1949. In 1956, first Chinese major started in University of Bucharest, introducing Chinese language education in the higher education system, covering education of Chinese language, Chinese literature, and Chinese culture courses. The graduates and professors have made great contribution to the mutual relationship between China and Romania. In 1998, Babes-Bolyai University in ClujNapoca began the "English +Chinese" major. In the same year, Chinese language education started in Alexandru Ioan Cuza University of Iaşi. In 2006, the Confucius Institute at "Lucian Blaga" University of Sibiu was established for the purpose of teaching Chinese and promoting Chinese culture, and subsequently came Cluj Babes-Bolyai University Confucius Institute in 2009, Confucius Institute at Transilvania University of Braşov in 2012 and Confucius Institute at University of Bucharest in 2013. In 2018, one of the Confucius classrooms of C.I. at LBUS became independent-Confucius Classroom of Ovidius University, and it turns out that there are four Confucius Institutes and one independent Confucius classroom in Romania up till 2021. Since then, Chinese teaching and the promotion of Chinese culture have developed tremendously in Romania.

\section{DEVELOP EXPLICIT CHARACTERISTICS AND ESTABLISH BRAND IMAGE OF SIBIU C.I.}

Confucius Institute at ULBS is the first C.I. co-built with Beijing Language and Culture University (BLCU) in China. BLCU is world-famous in international Chinese language education. In order to maintain an effective management and sustainable development, it is vital for Sibiu C.I to seek for explicit characteristics. On one hand, the curriculum of Chinese major in the university is revised based on the target of talents with qualified Chinese proficiency, on the other hand, we strengthen the training of teachers to fit in the requirement of the local education as well as the academic research on the Romanian students learning Chinese. Furthermore, we are devoted to more opportunities for Romanian public to know more about Chinese culture. In a word, we are motivating the comprehensive functioning of Confucius Institute, which integrates Chinese language teaching, cultural dissemination and academic research. It is of vital importance to establish brand image and offer support to those who are interested in learning Chinese language and learning about Chinese culture in Romania. 


\subsection{Characteristics in Teaching}

With the support of both BLCU and ULBS, Sibiu C.I. pays attention to drawing on the experience of teaching Chinese as a foreign language and the research results of foreign language education, focusing on the cultivation of students' language ability and international cultural literacy, and strives to create its own teaching characteristics. Since its founding in 1962, BLCU has trained some 160,000 foreign students from more than 180 countries and regions who are proficient in the Chinese language and familiar with the Chinese culture. BLCU has always been a leading liberal arts university in China with 12,000 students from all over the world in undergraduate, graduate and language training programs [3]. With the sufficient experts in Chinese teaching, Sibiu C.I. has tailored the courses as well as ways of teaching.

\section{Curriculum design and teaching mode}

It is of great importance for us to design long-term tailored courses for each group and each level of Chinese learners because teaching is not a one-time event, but a continuous process. The Chinse teaching of C.I usually include students from primary school, middle school, university and companies. Primary school teaching aims at cultivating pupils' interest in learning Chinese, and teaching basic Chinese characters and certain communicative skills by organizing various teaching activities relating to Chinese culture. For preparing students to enter universities, especially those for want to take Chinese language as their major in further education, secondary school teaching introducing preparatory education of university, which take the comprehensive Chinese course to training students' listening, speaking, reading and writing skills, and courses to enable students with basic understanding of Chinese history and culture, while leading them to evaluate their language proficiency with HSK exams. The goal of university teaching is to train applied Chinese talents for future sinologist, translators, interpreters or businessmen. The first and second year of Chinese major take the Chinese language skill training courses as the core, like listening, speaking, reading and writing, and courses of basic linguistics and cultures. The third year takes professional courses and cultural courses as the major courses, including thesis writing, current affairs news analysis, further education in translation and Chinese history, literature, culture and arts. Social training group will train the community beginners of Chinese language, targeting at daily communication, office Chinese, travel Chinese, etc. They are also offered calligraphy, painting, Tai Chi, handcraft and other courses introducing Chinese culture.

Our teaching is based on the combination of online and face-toface classroom teaching, which is called "Blended Learning" [4, $5,6,7]$. Blended learning, also known as hybrid learning, is an approach to education that combines online educational materials and opportunities for interaction online with traditional place-based classroom methods. It requires the physical presence of both teacher and student, with some elements of student control over time, place, path, or pace. The terms "blended learning", "hybrid learning", "technologymediated instruction", "web-enhanced instruction", and "mixedmode instruction" are often used interchangeably in research literature. Comparing with MOOC (Massive Open Online Course), SPOC (Small Private Online Course) [8] shows its advantage of taking the advantage of traditional classroom teaching and the advanced teaching technology of internet. SPOC fits for the learning group of Sibiu C.I., which has registered small classes of Chinese learners. In order to realize the pre-set effect of teaching and optimize each teaching process, we take the principle of the leading role of teachers in guiding, enlightening, and monitoring the teaching processes while students as the main body of the learning process with initiative, enthusiasm and creativity.

\section{Regular Teacher training}

The quality of teaching is the guarantee for the teaching with new technology and sticking to the teaching principle. In order to ensure and improve the quality of teaching, Sibiu C. I. has formulated the systems of pre-job training, collective lesson preparation and peer class observation. Every newly-coming Chinese teacher and volunteer teacher will attend professional training as well as lectures of culture difference introduction before staring the online or classroom teaching; all teachers collectively prepare lesson once every two weeks, with regard to Romanian students' characteristics, teaching materials, teaching process, teaching methods, etc. Each teacher is supposed to observe and listen to the other teachers' classes at least once a month, online or offline, and exchange experience and provide comments and discussion on the classes monitored. In addition, taking advantage of the academic resources of Beijing Language and Culture University, Sibiu C.I. also invite experts from Beijing Language and Culture University to give lectures regularly to help its teachers improve their teaching competence.

\subsection{Characteristics in culture promotion}

Some are saying that different from its name, Confucius Institutes is not focusing on Confucius' doctrine at all, which has aroused some discussion. Since its inception, Sibiu C.I. has attached great importance to imparting Confucian ideas and values. In the process of teaching, we blend the elements of benevolence, virtue and harmony of Confucianism into the teaching content, and promotes the spread of Confucianism on the common ground of Confucianism and modern western thought.

In the last 15 years since its establishment, the scale and the number of cultural activities held by Confucius Institute at LBUS have constantly expanded. Even when the Epidemic started at the beginning of 2020, Sibiu. C.I. kept on holding online and offline activities, with the average of more than 20 big and small cultural activities with nearly two-thousand participants each year. We have carried out innovations in the form of cultural activities, with the theme of "propriety, music, archery, riding, writing and arithmetic", and for the first time we presented Chinese national costume shows and started traditional Touhu game in "The 11th Chinese Bridge Competition for Secondary School Students in Romania". The "Spring Festival Celebration", the "Traditional Chinese Medicine Exhibition" and "Sibiu CI Confucius Cup" are among our brand activities around all the counties where we spread our Chinese programs. Through these activities, our students as well as other Romanians find a way to learn about Chinese culture and Chinese people.

\subsection{Academic characteristics}

Confucius Institute at LBUS attaches importance to academic research and strives to improve its influence through academics. On one hand, Confucius Institute at ULBS demonstrate all activities of Chinese program in the Journal Confucius [9] and publish Chinese teachers' research paper to accelerate exchange of experience and improve teaching. We hold seminars on teaching Chinese as a foreign language for teachers of Chinese, pushing hard for more research results. On the other hand, teachers are encouraged to attend academic conferences. Especially we get involved in the lectures of LBUS International Week, starting with 2 or 3 lectures on Chinese teaching, Chinese literature or Chinese culture, to later 5 lectures forming a small 
corner of Chinese theme, which at the same time is a contribution to the international exchange as we. The achievement in academic research has tremendously facilitate the development of Chinese teaching.

\section{TAKING THE LEARNERS AS THE CENTER AND INNOVATING POSITIVELY}

In order to provide practical tailored teaching, Sibiu C.I. has made innovations in the ways and means of promoting Chinese language based on the need of the local learners.

\subsection{Localization}

Sibiu C.I. is devoted to localization of teaching. Each teacher is required to analyze, study and solve problems based on the characteristics of Romanian learners of Chinese, based on taking the accumulated experience of other teachers. More importantly, we attach great importance to the localization of teaching materials. With our effort, we have translated Happy Chinese [10] into Romanian, which was published in 2016 and started to be published in 2018. Native teachers of Chinese are trained. On one hand, we actively selected outstanding Chinese major graduates to continue their study in China so as to enrich the reserve strength of local teachers; On the other hand, we have made efforts to help local teachers improve their teaching by inviting experts to give lectures online and offline as well. We held regular training program every year, track their teaching process, evaluate and guide their teaching.

\subsection{Boosting cultural activities by leveraging local momentum}

In order to bring Chinese culture closer to the local people, we take the chance of the local mature platform to demonstrate Chinese culture. "Researchers Night", held annually by LBUS, has great influence in the local society, with thousands of people participating. Sibiu C.I. has well prepared and actively participated in it every year, presenting different themes of "Modern China", "Chinese Music", "Chopsticks Competition", etc. Every year we also hold corresponding cultural activities on Romania's National Day, Martisor (Martisor is an authentic Romanian tradition, celebrated on March 1st with snowdrops, gifts, and little talismans with red and white strings), Children's Day, Christmas, which all have gained in popularity.

\subsection{Preparation of learning Chinese for the future}

According to a survey from the Ministry of Education of the People's Republic of China (MoE of PRC) [11], 492,185 international students, from 196 countries or regions, were studying at Chinese universities, institutes and other teaching agencies in 2018. It is an increase of 3013 more than those in 2017. Among them, 258,122 students accepted academic credential education, 85,062 master and doctoral students. It took $52.44 \%$ of the total amount of international students, which increased 16,579 more than those in 2017. A total of 63,041 students has won Chinese scholarships.

Besides few self-financed preparatory educational program, most preparatory educational programs are supported by scholarship from the headquarter of Confucius Institute or China Scholarship Council. With the support of scholarship, international students can study Chinese language for 1-2 years. After passing the related exams, they can start their studies from bachelor degree. If students passed HSK-4 or higher level, they could apply for university directly without the Chinese preparatory education, which means that students may start their university degree study immediately with the help of scholarship.

Sibiu Confucius Institute provides programs like the interestoriented Chinese language learning, optional Chinese courses, as well as Chinese preparatory education for high school students in Romania. We design the customized teaching plan, assist students prepare for HSK test, and help them to apply for academic credential education in Lucian Blaga University as well as university in China.

As we all know that opportunities and challenges co-exist. In the following part, we will analyze the feasibilities and challenges of our Chinese program in Sibiu C.I.

The feasibilities are as follows:

A. The increasing number of Chinese leaners, especially the number of secondary school students [12]. In 2007, Chinese course has been taken into the Romanian national education system, which provides the possibility for both primary and secondary school students to choose Chinese as their foreign language course. Furthermore, four Confucius Institutes and one independent Confucius Classroom have been set up respectively in Lucian Blaga University of Sibiu in 2006, Babes-Bolyai University in Cuj-Napoca, Transilvania University of Brasov, University of Bucherest, and Ovidius University of Constanta, among which the previous four universities all have Chinese major program. According to the survey from education department of the Chinese embassy in Romania, there were 12,000 Chinese learners in 2017 including about 50\% of secondary school students (around 6,000 students). The percentage remains high before the Epidemic started in 2020. When the secondary students join the Chinese preparatory program, it provides them with more possibilities: solid Chinese language proficiency for university Chinese major application; better possibility for applying scholarship to study in China as soon as entering or before into the Romania universities; highly recommendation from Sibiu C.I. when applying for university or scholarship; first-class Chinese university entrance to the Chinese language program (Beijing Language and Culture University).

B. China and Romania are deepening cooperation in various fields. As the development of Chinese economy after the reform and open-up policy, a number of enterprises settled in Romania, such as ZTE, Huawei, Red Dragon Chinese House, China Ocean Shipping Company, CTIEC etc. The Red Dragon Chinese House is the first company from China. After 25 years' operation, it has been the largest distributing center of Asian goods in Europe. The $90 \%$ goods in Red Dragon are from China, which not only satisfy Romanian people's needs in daily life, but also affect the whole Europe especially Moldova, Serbia, Hungary etc. The customers in Red Dragon are up to 25,000 per day, and up to 40,000 to 50,000 persons per day during holidays. As the hi-tech and new industry, Huawei proposed "the seeds for the future" telecom program in August 2014, cooperating with 7 local universities such as Politechnic University of Bucharest, University of Craiova, Alexandru Ioan Cuza University etc., aiming to help excellent students in Romania to study in China. It is supported by the Ministry of Communications and Information Society of Romania and the Ministry of National Education of Romania. The fast development of Chinese enterprises brings a number of opportunities and better working environment. It provides a lot of job positions for the Romanian Chinese language learners. Sibiu C.I has built up the bridge between our Chinese major graduates and Chinese enterprises in Romania and we have 
succeeded in recommending our graduates working for China Embassy in Romania, Huawei, Miniso, etc.

C. It depends on the friendly history and further cultural communication between Chinese and Romanian government. China and Romania established diplomatic relations on 5th October 1949. Then, China and Romania experienced friendly cooperation and development of 69 years. To deepen the close relationship, China and Romania established mutual cooperation in politics, economy, culture, technology, judiciary etc. The comprehensive cooperation demands for the messenger to assist the communication between China and Romania. It is of vital importance to help those who love to learn Chinese language and are interested in Chinese culture. We believe that our Romanian students will work hard for the better future of China and Romania.

However, opportunities come along with challenges. The challenges in the process of development of preparatory education are as follows:

A. The largest obstacle is the recognition of degree from China. Generally speaking, the recognition of Chinese education degree, from the Ministry of Education of Romania and the Romanian government, is not quite popular at the time. Students with a Chinese education degree could not make the best advantage of it. China Embassy in Romania has been discussing further cooperation agreement with the Ministry of Education of Romania in order to improve the mutual understanding at the academic and education field. Under this condition, more Romanian students would go to China to seek for higher education.

B. Higher education without scholarship is expensive. According to the standard from MoE of PRC, the tuition for bachelor students is between 2,043 to 3,793 dollars per year. The average family find it hard to afford the expenses including the tuition, travel tickets, hotel and living costs when the students apply for higher education in China without any financial support of scholarship.

C. Lack of information about modern China. "Seeing is believing". China is a developing country and is seeking for the common prosperity of humankind. It is easy saying that doing, so every step of "doing" needs mutual understanding and handin-hand effort. Some people still have not got enough information about how the life is going on in China. Sibiu C.I. is working for bringing more information in different aspects and fields to Romania and helping those who want to take a look by themselves in China. Thus, we may achieve mutual understanding and accelerate cooperation.

Our preparatory education program will provide instructions for Romanian students to study Chinese language, passing HSK-3 or HSK-4 before entering into university, making you one of the best students, preparing you for a brighter future.

\section{CONCLUSIONS}

To summarize, Sibiu C.I. will stick to our original aspiration and keep our mission firmly in mind that we are building the bridge between people of Romania and China by helping those who are interested in Chinese language and Chinese culture. We will endeavor to strengthen the characteristics and innovation of the development, making the flower of Chinese language blossom in Romania.

\section{REFERENCES}

1. Ministry of Education of P.R.C. (2021). Rretrieved from

http://www.moe.gov.cn/jyb_xxgk/xxgk_jyta/yuhe/202

111/t20211104_577702.html. Accessed June, 2021

2. Ministry of Education of Romania. Retrieved from: https://www.edu.ro/programe-specifice-pentruconcurs-titularizare-cultur\%C4\%83-general\%C4\%83. Accessed June, 2021

3. Beijing Language and Culture University. Retrieved from: https://admission.blcu.edu.cn/en/10/list.htm. Accessed June, 2021

4. Singh, H.; Reed, C. A (2001) White Paper: Achieving Success with Blended Learning. Retrieved from: http://www.leerbeleving.nl/wbts/wbt2014/blendce.pdf. Accessed July, 2021

5. Graham, Charles R.; Woodfield, Wendy; Harrison, J. Buckley (2013). A framework for institutional adoption and implementation of blended learning in higher education. The Internet and Higher Education. Blended Learning in Higher Education: Policy and Implementation, 18, 4-14.

6. Martyn, M. (2003). The hybrid online model: Good practice. Educause Quarterly, 18-23.

7. Saritepeci, Mustafa; et al. (2015). The effect of blended learning environments on student motivation and student engagement: A study on social studies course. Education and Science, doi: 10.15390/EB.2015.2592

8. Coughlan, S. (2013) Harvard plans to boldly go with 'Spocs'. Retrieved from: http://www.bbc.com/news/business-24166247, 201309-24. Accessed July, 2021

9. Caietele Confucius Deva, COLOFON Printing house ISSN: 2537-3579/ISSN-L: 2537-3579

10. Li, X.Q.; Liu, Q.S.; Liu, X.Y (2013) Happy Chinese Beijing: People's Education Publishing House

11. Ministry of Education of P.R. China. Retrieved from: http://www.moe.gov.cn/jyb_xwfb/gzdt_gzdt/s5987/20 1904/t20190412_377692.html. Accessed July, 2021

12. Hartman, J.; Moskal, P.; Dziuban, C (2005). Preparing the academy of today for the learner of tomorrow. Retrived from: https://www.educause.edu/researchand-publications/books/educating-netgeneration/preparing-academy-today-learnertomorrow. Accessed July, 2021 